\title{
Assessing the effectiveness of a large marine protected area for
}

\section{reef shark conservation}

Timothy D. White ${ }^{1 \dagger}$, Aaron B. CARlisle ${ }^{1}$, David A. Kroodsma ${ }^{2}$, Barbara A.

Block $^{1}$, Renato Casagrandi ${ }^{3}$, Giulio A. De Leo ${ }^{1}$, Marino Gatto $^{3}$,

FiORENZA MiCHELI $^{1}$, Douglas J. MCCAULEY ${ }^{4}$ 
24 ABSTRACT: Large marine protected areas (MPAs) have recently been established

25 throughout the world at an unprecedented pace, yet the value of these reserves for mobile

26 species conservation remains unclear. Reef shark populations continue to decline even

27 within some of the largest MPAs, fueling unresolved debates over the ability of protected

28 areas to aid mobile species that transit beyond MPA boundaries. We assessed the

29 capacity of a large MPA to conserve grey reef sharks - a Near-Threatened species with a

30 widespread distribution and poorly understood offshore movement patterns - using a

31 combination of conventional tags, satellite tags, and an emerging vessel tracking

32 technology. We found that the $54,000 \mathrm{~km}^{2}$ U.S. Palmyra Atoll National Wildlife Refuge

33 in the central Pacific Ocean provides substantial protection for grey reef sharks, as two-

34 thirds of satellite-tracked sharks remained within MPA boundaries for the entire study

35 duration. Additionally, our analysis of $>0.5$ million satellite detections of commercial

36 fishing vessels identified virtually no fishing effort within the refuge and significant

37 effort beyond the MPA perimeter, suggesting that large MPAs can effectively benefit reef

38 sharks and other mobile species if properly enforced. However, our results also highlight

39 limitations of place-based conservation as some of these reef-associated sharks moved

40 surprising distances into pelagic waters (up to $926 \mathrm{~km}$ from Palmyra Atoll, $810 \mathrm{~km}$

41 beyond MPA boundaries). Small-scale fishermen operating beyond MPA boundaries (up

42 to $366 \mathrm{~km}$ from Palmyra) captured $2 \%$ of sharks that were initially tagged at Palmyra,

43 indicating that large MPAs provide substantial, though incomplete, protection for reef

44 sharks.

45 KEYWORDS: Carcharinus amblyrhynchos, satellite telemetry, vessel tracking, marine

46 protected areas, fisheries, Automatic Identification System 
HIGHLIGHTS

- We used two tag types and vessel tracking to assess a large marine protected area.

- Large MPAs offer substantial, though not absolute, protection for reef sharks.

- Most grey reef sharks stayed within the MPA near minimal observed fishing effort.

- Two swam past the largest possible MPA limits (up to $926 \mathrm{~km}$ into open water).

- $2 \%$ of sharks tagged in the MPA were caught on atolls $223-366 \mathrm{~km}$ away from the MPA.

\section{INTRODUCTION}

56 Marine protected areas (MPAs), which restrict fishing in order to aid conservation and

57 fishery production, have become increasingly common in coastal waters over the last

58 several decades (Lubchenco et al., 2003; Gaines et al., 2010; McCauley et al., 2015). A

59 new frontier of MPA design has recently emerged: the creation of large, remote, pelagic

60 MPAs (Lubchenco and Grorud-Colvert, 2015). The rapid establishment of these large

61 MPAs, some spanning over one million $\mathrm{km}^{2}$, has nearly doubled the total area of

62 protected ocean on Earth in just five years (McCauley et al., 2014). Surrounding this

63 unprecedented and fast-moving trend in global ocean management, there is considerable

64 uncertainty about which species will benefit from MPAs of this size (De Santo, 2013;

65 Pala et al., 2013).

66 The advantages of large MPAs for highly mobile species are particularly unclear,

67 as the movements of many marine mammals, turtles, sharks, tunas, and other pelagic fish

68 can dwarf even the largest MPAs (Game et al., 2009; Block et al., 2011; Sibert et al.,

69 2012; Dueri and Maury, 2013). The presumed ecological importance of large and more

70 mobile marine predators to marine ecosystem functioning (Bouchard and Bjorndal, 2000;

71 Ferretti et al., 2010; Estes et al., 2011; McCauley et al., 2015) makes it essential to 
72 determine their relationship to large MPAs. To assess the benefits of large MPAs for

73 mobile species, it is critical to determine both the proportion of time that individuals

74 spend outside MPA boundaries, and the severity of mortality risks that occur beyond

75 these boundaries (Graham et al., 2012; Rosenbaum et al., 2013). While spillover of

76 populations from MPAs to adjacent waters may benefit nearby fisheries (Roberts et al.,

77 2001; Halpern et al, 2009), under some conditions anthropogenic impacts outside an

78 MPA can outpace reproduction and recruitment inside an MPA, resulting in population

79 declines (Moffitt et al., 2009). Incomplete protection of an individual's activity space

80 may be especially detrimental to shark species due to their low fecundity, late age at

81 sexual maturity, and high susceptibility to fishing pressure (Cortés et al., 2000; Dulvy et

82 al., 2014). Recent shark population declines within some large MPAs have fueled

83 uncertainty about the efficacy of these reserves for mobile species and the ability of

84 nations to reduce fishing effort across such vast regions (Graham et al., 2010; White et

85 al., 2015).

86 Despite the fact that reef shark conservation is an explicit goal of many large

87 MPAs (Koldewey et al., 2010; Davidson et al., 2012; Dulvy et al., 2013), the offshore

88 movement patterns of some species are not well resolved and anthropogenic impacts

89 surrounding large MPAs are rarely quantified, so it remains unclear how much protection

90 they will truly receive from these measures. Here, we assessed the effectiveness of a large

91 MPA for conserving one of the most historically abundant sharks in Indo-Pacific coral

92 reef ecosystems: the grey reef shark (Carcharinus amblyrhynchos). Grey reef sharks can

93 comprise up to $46 \%$ of upper trophic level biomass in unfished reef ecosystems

94 (Stevenson et al., 2007; Friedlander et al., 2014). However, grey reef sharks have 
95 experienced severe population declines across some of their Indo-Pacific distribution and

96 are listed as Near Threatened in the International Union for Conservation of Nature's

97 (IUCN) Red List of Threatened Species (Robbins et al., 2006; IUCN 2015). Grey reef

98 shark movements have been studied within individual atolls and coastal regions using

99 acoustic telemetry (McKibben and Nelson, 1986; Heupel et al., 2010; Barnett et al., 2012;

100 Espinoza et al., 2015a; Espinoza et al., 2015b) - a method that records the presence of

101 tagged individuals when they approach nearshore acoustic receivers - but their broader,

102 offshore movements when away from stationary receivers remain poorly understood.

103 Stable isotope analysis of grey reef shark tissue has revealed heavy reliance on pelagic

104 prey (McCauley et al., 2012), but it is unclear if this putative trophic subsidy reflects the

105 movements of the sharks to pelagic habitats or movement of pelagic prey into nearshore

106 habitats.

107 We conducted our investigation of large MPA effectiveness on the northern Line

108 Islands archipelago in the central Pacific Ocean. Within this archipelago, the U.S.-

109 managed Palmyra Atoll National Wildlife Refuge $\left(54,000 \mathrm{~km}^{2}\right.$, fishing fully prohibited)

110 is located several hundred kilometers from three inhabited and fished atolls that partially

111 comprise the nation of Kiribati (Fig. 1). Protected reefs in this region host large

112 populations of grey reef sharks and other mobile predators, while the fished reefs of

113 Kiribati host dramatically lower predator densities (Sandin et al., 2008). The boundaries

114 of the protected area at Palmyra Atoll have been expanded multiple times since 2001, and

115 similarly the boundaries of the Papahānaumokuākea Marine National Monument in the

116 Northwestern Hawaiian Islands were substantially expanded in August 2016, making

117 discussions of reserve design in this area locally relevant and timely. 
The specific goals of this study were to 1) determine the amount of time that grey

119 reef sharks spend outside of historical and contemporary MPA boundaries by deploying

120 conventional tags and satellite tags on this species at Palmyra Atoll, 2) assess the

121 interaction dynamics between grey reef sharks and both commercial and small-scale

122 fishermen by recovering conventional tags from fishermen and quantifying commercial

123 fishing effort via a recently-developed remote sensing capabilities, and 3) evaluate how

124 locally relevant changes in MPA size may shape a species' exposure to risk. The

125 combination of both satellite telemetry and conventional tagging provides us with unique

126 insight into the oceanic movements and potential conservation strategies for this key

127 species.

128 An important additional aim of this work was to demonstrate the value of cross-

129 evaluating data on the spatial ecology of large marine predators obtained via animal

130 tracking with newly available data on the spatial ecology of human predators (i.e.

131 fishermen) obtained via vessel tracking. Historically such comparisons have been limited

132 as high-resolution fishing vessel data have either not been available or have been kept

133 private by regional management authorities (but see Queiroz et al., 2016). The recent

134 release of publically accessible data on fishing vessel activity and the development of

135 new behavioral filtering algorithms to interpret these vessel tracks (McCauley et al.,

136 2016) opens the door to novel analytical opportunities. Using information derived from

137 the Automatic Identification System (AIS), a globally abundant vessel transmitting

138 system, we generated a spatially explicit quantification of industrial fishing effort

139 throughout the region where we tracked grey reef sharks. We evaluated how fishery

140 effort density related to the boundaries of the focal MPA in our study region and 
141 examined interactions between shark behavior and the behavior of fishermen.

142 Collectively these diverse forms of insight into how coastal sharks use space, combined

143 with spatially explicit views of how fishermen use some of the same ocean space

144 empowers us to make much more informed decisions about how best to tailor marine

145 management tools to meet conservation objectives.

147 2. MATERIALS AND METHODS

\section{$148 \quad 2.1$ Study area}

149 We tracked the movements of grey reef sharks and fishermen in relation to an MPA in 150 the central Pacific Ocean $\left(1-11^{\circ} \mathrm{N}, 152-167^{\circ} \mathrm{W}\right)$. This study focused on four atolls within

151 the northern Line Islands. Palmyra Atoll is located with a large, no-take marine protected 152 area $\left(54,000 \mathrm{~km}^{2}\right)$ that is federally managed by the U.S. Fish and Wildlife Service, while

153 Teraina, Tabuaeran, and Kiritimati are fished islands within the Republic of Kiribati (Fig.

154 1). Palmyra Atoll is uninhabited except for a small number $(<20)$ of visiting researchers,

155 research station staff, and wildlife refuge employees. The area within a 12 nautical mile

156 (NM; $22.2 \mathrm{~km}$ ) radius of Palmyra Atoll was first established as a National Wildlife

157 Refuge (NWR) in 2001. In 2009, the boundaries of Palmyra Atoll NWR were expanded

158 to $50 \mathrm{NM}(92.6 \mathrm{~km})$ through the establishment of the Pacific Remote Islands Marine

159 National Monument (PRIMNM). PRIMNM consists of Palmyra Atoll and 6 other remote

160 atolls, all protected out to 50NM from fishing and other extractive activities. In 2014, the

161 MPA boundaries were expanded out to $200 \mathrm{NM}(370.4 \mathrm{~km})$ at 3 of those 7 atolls (Jarvis

162 and Wake Island and Johnston Atoll), bringing the total protected area to nearly 1.3

163 million $\mathrm{km}^{2}$. Though Palmyra's boundaries were considered for an extension to $200 \mathrm{NM}$, 
164 it boundaries remained fixed at 50 NM. This 200 NM boundary is the extent of the U.S.

165 exclusive economic zone (EEZ), and as such it is the maximum MPA limit that any

166 nation can independently manage under current international law. Expansions of this

167 scale are currently underway at other locations in the Pacific Ocean; the August 2016

168 expansion of the Papahānaumokuākea Marine National Monument's boundaries from 50

$169 \mathrm{NM}$ to $200 \mathrm{NM}$ brought its total protected area to over 1.1 million $\mathrm{km}^{2}$, making it the 170 world's largest MPA at the time.

171 In contrast with the protected areas of PRIMNM, the islands of Teraina,

172 Tabuaeran, and Kiritimati are respectively inhabited by 1690, 1960, and 5586 people

173 (Tekaieti, 2012). Teraina, Tabuaeran, and Kiritimati are located a distance of $223 \mathrm{~km}$,

$174366 \mathrm{~km}$, and $665 \mathrm{~km}$ from Palmyra Atoll $(113 \mathrm{~km}, 255 \mathrm{~km}$, and $548 \mathrm{~km}$ from the MPA

175 boundary). The residents of these islands are heavily dependent upon fishing for

176 subsistence and economic opportunity (Tekaieti, 2012). Small-scale shark fisheries and

177 the shark fin trade operate on all three of these islands, though the origins and biomass of

178 sharks that are captured in these fisheries are currently unknown. Line Islands small-scale

179 fishermen primarily operate out of 4-5 m aluminum skiffs and wooden canoes. Since

180 Kiribati fishermen generally do not leave sight of their islands due to a lack of

181 navigational equipment and limitations in gasoline availability, these fishermen do not

182 have the range to make the $446 \mathrm{~km}$ to $1330 \mathrm{~km}$ round-trip journey to illegally fish at 183 Palmyra Atoll.

$185 \quad 2.2$ Conventional tagging and small-scale fisheries mortality 
186 In order to measure the movements and observe mortality of grey reef sharks from

187 Palmyra NWR to the small-scale fisheries operating beyond the MPA boundary, we

188 deployed 262 numbered dorsal fin tags (Dalton Rototags, Newark, United Kingdom) on

189 grey reef sharks during October 2006 - July 2009. Each of these conventional tags were

190 imprinted with a unique identification number. We captured sharks on the forereef of

191 Palmyra Atoll using barbless hooks and handlines. We recorded sex and total length (TL)

192 before releasing the animals. All tagging work was conducted under U.S Fish and

193 Wildlife Service permit \# 13810.

194 We calculated the percentage of tags that were recovered by Kiribati fishermen as

195 a minimum estimate of interisland movements and small-scale fisheries mortality. We

196 actively searched for tags recovered by fishermen on the islands of Teraina, Tabuaeran,

197 and Kiritimati in 2007, 2009, and 2013 (197 days total). In addition, we raised awareness

198 of the tagging program through posted notices and public discussions at village halls,

199 radio interviews, and direct conversations with regional Kiribati fisheries officers, local

200 fishermen, and shark fin retailers. Local fisheries agents based on each island were

201 contracted to collect and report tags that were recovered while we were not present. We

202 physically retrieved all reported tags in order to verify their authenticity and to record the

203 recovery location and date from fishermen.

204

$205 \quad$ 2.3 Satellite tagging and kernel utilization distribution analysis

206 In order to gain a higher resolution understanding of large-scale shark movements, we

207 deployed 11 fin-mounted satellite tags on adult grey reef sharks at Palmyra Atoll NWR in

208 May and August 2013 (Table 1). Sharks were captured on handlines as described above. 
209 We used position-only SPOT tags (SPOT5, Wildlife Computers, Seattle, Washington,

210 USA). The tags were not programmed to record temperature because this reduces battery

211 life, and our primary objective was to record movements with respect to MPA boundaries

212 for as long as possible. SPOT tags transmit a location and accuracy estimate when the

213 dorsal fin breaks the surface of the water, which is a behavior that has been observed

214 during grey reef shark feeding events on pelagic prey at Palmyra Atoll (McCauley et al,

215 2012). To estimate the frequency with which sharks left the atoll for pelagic habitats, we

216 used ArcGIS 10.0 to calculate the percentage of these hits that fell outside a $500 \mathrm{~m}$

217 isobath surrounding Palmyra Atoll. We used Argos detections to assess movements

218 away from the atoll and not daily position estimates (see below) because they have the

219 greatest spatial resolution and therefore are most appropriate for atoll-scale calculations

220 (Papastamatiou et al., 2010). Additionally, we calculated kernel utilization distributions

221 (KUD) using filtered Argos detections through the Geospatial Modeling Environment

222 version 0.7 .3 .0 (www.spatialecology.com/gme) in order to measure the activity space (95

$223 \%$ KUD) and core area (50 \% KUD) of individual animals (Papastamatiou et al., 2010;

224 Olson et al., 2012; Carlson et al., 2014). To avoid bias that may result from differences in

225 detection frequency, we first filtered detections to one point per day of data by

226 calculating the median detection (Olson et al., 2012; Carlson et al., 2014).

\subsection{Analysis of shark movements across management boundaries}

229 The error radius of a SPOT tag detection is determined by the orientation of Argos

230 receiving satellites at the time of transmission. Satellite detections fall into 7 different

231 location classes (LC) of varying accuracy $(3,2,1,0, \mathrm{~A}, \mathrm{~B}, \mathrm{Z})$. For our analyses, we 
232 accepted locations from LC3 to LCB. LC3-LC1 have error estimates ranging from $250 \mathrm{~m}$

233 to $1500 \mathrm{~m}$ as reported by Argos, and error estimates for LC0 - LCB were based on peer-

234 reviewed, empirical estimates that range from $4180 \mathrm{~m}$ to 10,280 $\mathrm{m}$ (Costa et al., 2010).

235 In order to determine the amount of time that sharks spent outside of historical

236 and contemporary MPA boundaries, we estimated daily shark positions and $95 \%$

237 credible intervals using a Bayesian state-space model (SSM) that explicitly accounted for

238 uncertainty in satellite detections and the uneven distribution of detections over time

239 (Jonsen et al., 2005). The SSM that we applied is fully described in Block et al, 2011 and

240 has been previously shown to produce robust estimates of the movements of shark

241 species and other taxa (Block et al., 2011; Winship et al., 2012). This SSM interpolated

242 across gaps in the satellite detections that were $\leq 20$ days (Bailey et al., 2008; Block et

243 al., 2011). We did not attempt to estimate changes in animal behavioral modes via a

244 switching model, as our primary objective was to determine the movements of the tagged

245 animals in relation to MPA boundaries. The relevant MPA boundaries considered were

246 the 12 NM limit (the boundary of Palmyra NWR from 2001-2009), 50 NM limit (the

247 boundary of Palmyra NWR from 2009-present), and 200 NM limit (U.S. EEZ; the current

248 boundaries of other large MPAs in PRIMNM and the maximum potential boundary for

249 Palmyra NWR or other national jurisdictions). Sharks were considered to be outside an

250 MPA boundary if their mean position estimate (and correspondingly, over $50 \%$ of the

251 uncertainty estimate) fell outside of that limit.

252

$253 \quad 2.5$ Automatic identification system (AIS) analysis of commercial fishing pressure 
254 We determined patterns of international commercial fishing effort near the Line Islands

255 by analyzing satellite detections of vessel AIS transmissions. We analyzed the tracks of

256 registered longline and purse seine fishing vessels that entered our study region $\left(1-11^{\circ} \mathrm{N}\right.$,

$257152-167^{\circ} \mathrm{W}$ ) from 1 January 2013 to 31 December 2014 . Fishing events were identified

258 using a machine learning algorithm that used frequency of vessel course changes and

259 vessel speed to calculate a "fishing score," or the likelihood that observed vessel tracks

260 are indicative of distinctive fishing behaviors (McCauley et al., 2016). Fishing scores

261 range from 0 to 1 , where 0 is a vessel that is least likely to be fishing, and 1 is a vessel

262 that is very likely fishing. A linear regression analysis has previously demonstrated that

263 algorithm-estimated fishing effort is highly correlated with effort estimates derived from

264 fisheries reporting agencies (McCauley et al., 2016). A shared limitation of AIS and

265 traditional vessel tracking technologies is that illegal fishing vessels will not be detected

266 if they do not transmit signals. Additionally, smaller vessels are not required to transmit

267 AIS so satellite analysis of AIS data primarily focuses on larger, industrial vessels; an

268 estimated $71 \%$ of large fishing vessels (>24 m) regularly transmit AIS (McCauley et al.,

269 2016). We aggregated "likely fishing days," defined as fishing score $\geq 0.5$, into $0.25^{\circ}$ by

$270 \quad 0.25^{\circ}$ grid cells. Fishing days detected within three nautical miles of land were discarded

271 since vessels exhibit more frequent changes in speed and course when navigating coastal

272 waters and ports.

273

274 3. RESULTS

275 3.1 Tags recovered beyond the MPA from small-scale fisheries 
276 We deployed 262 conventional tags at Palmyra Atoll on grey reef sharks that ranged from

27790 to $175 \mathrm{~cm}$ in total length (TL). Five of our 262 conventional tags deployed within

278 Palmyra NWR were recovered from small-scale, nearshore shark fishermen in Kiribati

279 (Fig. 1; Table 2). These sharks were reported to have been caught on the forereef of

280 Tabuaeran (3 tags; $366 \mathrm{~km}$ from Palmyra tagging site) and Teraina (2 tags; $223 \mathrm{~km}$ from

281 Palmyra tagging site). No tags were recovered on Kiritimati during this study. Eighty-five

282 percent of the 262 conventionally tagged sharks were female and all 5 of the recovered

283 tags were from female sharks (Table 2). Tagged sharks were at liberty for a mean of 587

284 (SE 247) days prior to capture. These 5 sharks were all captured with single-hook

285 handlines aboard 4-5 m aluminum skiffs.

$287 \quad 3.2$ Reef shark movements in pelagic waters

288 Eleven SPOT tags were deployed on grey reef sharks that ranged from $143 \mathrm{~cm}$ to $159 \mathrm{~cm}$

289 in TL. From these deployments we obtained a total of 1280 satellite detections from 6

290 tagged sharks and analyzed 880 detections that were LC3-LCB (Table 1). All 6 sharks

291 were detected in pelagic waters away from the atoll; the median percentage of detections

292 per animal beyond the $500 \mathrm{~m}$ isobath was $28 \%$, with values for individual animals

293 ranging from $6 \%$ to $97 \%$ (Table 1). Three of our 11 satellite tags failed to transmit any

294 data and 2 tags reported data for 3 or less days, so these tags were not included in

295 analyses. The 6 successful SPOT tags transmitted for an average of 246 (SE 65) days

296 (Table 1). Although we tagged 4 female and 7 male sharks, all 6 of the successful tracks

297 came from male sharks. 
300 The SSM analysis produced a total of 919 daily position estimates for the 6 SPOT tagged

301 sharks, with a mean of 153 (SE 45) daily position estimates per animal (Fig. 1). A

302 relatively small percentage of daily positions beyond MPA boundaries had error

303 estimates that overlapped with MPA boundaries ( $24 \%$ for $12 \mathrm{NM}, 14 \%$ for $50 \mathrm{NM}$, and

$3043 \%$ for $200 \mathrm{NM}$ ); in these cases positions were considered outside the MPA boundary if

305 the mean position estimate fell beyond the boundary. Based on these position estimates, 4

306 of the 6 SPOT tagged sharks remained inside Palmyra MPA's current 50 NM boundaries

307 for the entire study duration, while 2 sharks ventured outside for $9 \%$ and $57 \%$ of their

308 daily position estimates (Table 1). All 6 sharks transited beyond the historical 12 NM

309 boundaries of Palmyra NWR for a median of $5 \%$ of their daily position estimates (range:

$3101 \%$ to $64 \%$ ). Two sharks were detected outside of the 200 NM limit (the U.S. EEZ

311 boundary) for $3 \%$ and $46 \%$ of their daily location estimates. The median maximum

312 linear distance from Palmyra Atoll's $500 \mathrm{~m}$ isobath for these 6 sharks was $66 \mathrm{~km}$, with a

313 range of 19 to $926 \mathrm{~km}$. The shark that traveled the furthest reached a maximum linear

314 distance of $908 \mathrm{~km}$ from the previous 12 NM MPA boundary surrounding Palmyra Atoll,

$315810 \mathrm{~km}$ from the current 50 NM MPA boundary, and $618 \mathrm{~km}$ from the $200 \mathrm{NM}$ boundary

316 (Table 1).

\section{$318 \quad 3.4$ Activity spaces and core areas}

319 Activity space (95 \% KUD) and core area (50 \% KUD) estimates for SPOT-tagged grey

320 reef sharks were highly variable across individuals. The median activity space was 933

$321 \mathrm{~km}^{2}$ and median core area observed was $154 \mathrm{~km}^{2}$ (Table 3). Four activity spaces were 
322 fully contained within the current MPA boundaries, while 2 activity spaces included

323 pelagic waters outside the current MPA and U.S. EEZ. The most mobile shark that we

324 observed had an activity space of $412,189 \mathrm{~km}^{2}$ and a core area of $106,049 \mathrm{~km}^{2}$.

325

$326 \quad 3.5$ Overlap of shark habitat with commercial fisheries

327 Within the study region, we analyzed 593,807 AIS detections with behavioral algorithms

328 (McCauley et al., 2016) that identified 6752 total days of fishing activity exhibited by

329151 unique longliners and 42 unique purse seiners in 2013-2014. Virtually no fishing

330 pressure was observed within Palmyra NWR (1 fishing day over two years) and

331 negligible effort was observed in the U.S. EEZ (6 fishing days) (Fig. 2). A hotspot of

332 likely fishing days (up to 51 fishing days in a 0.25 degree grid cell) was recorded directly

333 outside the MPA's southeastern border and the U.S. EEZ. The AIS devices of the 193

334 detected fishing vessels were registered to 12 different nations distributed across Asia,

335 Oceania, Europe, North America, Central America, and South America (Fig. 3). South

336 Korean ships comprised $62 \%$ of detected fishing vessels (103 longliners and 13 purse

337 seiners).

338

339 4. DISCUSSION

340 Our results demonstrate that large MPAs like the U.S. Pacific Remote Islands Marine

341 National Monument provide substantial, though incomplete, protection for grey reef

342 sharks. We analyzed the satellite tracks of grey reef sharks and found that the majority of

343 tag detections occurred within Palmyra Atoll National Wildlife Refuge (Fig. 1; Table 1).

344 Two thirds of the satellite tagged sharks were exclusively detected within this MPA, for 
up to 1.27 years post release. Activity spaces (95\% KUD) and core areas (50\% KUD) of

346 habitat utilization for these sharks were centered on Palmyra Atoll and the surrounding

347 pelagic waters, well within MPA boundaries. The median activity space of all tagged

348 sharks was $933 \mathrm{~km}^{2}$, less than $2 \%$ of Palmyra NWR's $54,126 \mathrm{~km}^{2}$ of protected area

349 (Table 3). These results offer support for the conclusion that large MPAs can offer

350 meaningful amounts of protection for mobile species with patterns of space use like grey

351 reef sharks.

352 Importantly, we also found that grey reef sharks displayed a surprising diversity

353 of movement patterns with some individuals swimming great distances that took them

354 well beyond the boundaries of this focal large MPA. For an animal that is believed, as is

355 eponymously implied, to be a quintessential reef-associated species (Compagno, 2001;

356 Randall, 2007) it is indeed surprising that up to $97 \%$ of satellite detections for one tagged

357 individual occurred in the pelagic environment (Table 1). We recorded the largest known

358 movement of a grey reef shark; a SPOT-tagged shark swam across $926 \mathrm{~km}$ of pelagic

359 waters, reaching a maximum linear displacement of $810 \mathrm{~km}$ beyond the MPA boundary

360 (Fig. 1; Table 1). To our knowledge, the maximum-recorded movement of a grey reef

361 shark, measured via stationary acoustic telemetry stations near the Great Barrier Reef, is

$362134 \mathrm{~km}$ (Heupel et al., 2010). Our satellite-derived value of $926 \mathrm{~km}$ increases the upper

363 bound of observed mobility by sevenfold.

364 Approximately half of the daily location estimates for the farthest travelling

365 individual in this study occurred outside the MPA, and portions of its activity space and

366 core area were located over $900 \mathrm{~km}$ from Palmyra Atoll. A second shark was detected

$367182 \mathrm{~km}$ from Palmyra Atoll (88 $\mathrm{km}$ beyond the current MPA boundary). These offshore 
movements, considered alongside previous isotopic analysis, support the hypothesis that

369 grey reef sharks may play an ecologically important role in maintaining ecosystem

370 connectivity between reefs and pelagic environments (McCauley et al., 2012). While the

371 majority of grey reef sharks remain inside the MPA and receive substantial protection,

372 these observations also highlight the possible limitations of the protection that large

373 MPAs can provide to highly mobile species. As satellite tracking and large MPA

374 establishment both continue to advance, we must consider that additional reef or coastal

375 species may in fact make large-scale movements, which may compromise large MPA

376 effectiveness for some species depending on the scale of movements and fishing pressure

377 outside the MPA. Acoustic tracking of grey reef shark movements has suggested that

378 relatively small MPAs (e.g., $15 \mathrm{~km}^{2}$ ) may be beneficial to grey reef shark populations

379 (Barnett et al., 2012), while the satellite and conventional tag data presented here suggest

380 that much larger MPAs are ideal. Continued tagging efforts and analyses of fishing effort

381 will bring an improved understanding of which species may or may not be likely to

382 benefit from large MPAs.

383 While the observation of pelagic movement patterns in grey reef sharks via

384 satellite telemetry and conventional tagging improves our understanding of reef shark

385 ecology and conservation, we caution that the interpretations of the spatial ecology that

386 we report are derived from a relatively low sample size $(n=262$ conventional tags

387 sharks, $\mathrm{n}=6$ successful satellite tags). All methods for tracking animal movements

388 provide a limited view of dynamic behavior; for example, acoustic telemetry may lead to

389 underestimates of activity space size since it does not capture offshore movements away

390 from coastal receivers, the density of satellite telemetry data is often limited by the time 
391 that tagged animals spend near the surface, and both methods are temporally restricted by

392 the battery life of electronic tags. Our estimates of grey reef shark movements may be

393 larger if sharks could be studied on time scales longer than our 8.1 month mean tag life.

394 Additionally, since SPOT tags transmit location when the tag breaks the water surface, it

395 is very possible that activity spaces are larger than recorded since individuals may have

396 undertaken additional movements in deeper waters. More will certainly be learned by

397 replicating this work on a larger number of individuals and examining potential for

398 geographic and environmental variability in space use by this species.

399 The recovery of 5 conventional tags (initially deployed at Palmyra Atoll) by

400 Kiribati fishermen on islands that are $223 \mathrm{~km}$ and $366 \mathrm{~km}$ from Palmyra provides two

401 additional insights. All 5 of the recovered conventional tags were from female sharks,

402 and all successful satellite tracks came from male sharks. Combining both tagging results

403 therefore indicates that both male and female grey reef sharks undertake interisland

404 transit and substantial pelagic movements. The infrequent detections of satellite-tracked

405 females deserve further exploration but may be the result of behavioral differences

406 between sexes, stochasticity, or reduced Argos satellite coverage across tropical latitudes

407 (Breed et al., 2012). Additionally, the recovery of conventional tags from shark fishermen

408 underscores the importance of aligning the scales of marine policy and spatial ecology of

409 conservation targets. The $2 \%$ rate of tag recovery from Kiribati (5 out of 262 tags)

410 should be taken as a minimum estimate of grey reef shark mortality from small-scale

411 fishermen in Kiribati, as some animals may have shed tags over time, and we are unlikely

412 to have received $100 \%$ of recovered tags given the remoteness of Kiribati and the

413 associated challenges in communication. The overall rate of fishing mortality for grey 
414 reef sharks tagged at Palmyra Atoll is likely higher than $2 \%$ because international fishing

415 vessels may have recovered additional tags that went unreported.

416 Our capacity, for the first time, to summarize publically accessible data on fishing

417 activity along the perimeter of large MPAs, like Palmyra, provides an exciting and

418 sobering view of the significance of the observed movements of grey reef sharks beyond

419 MPA boundaries. By behaviorally processing AIS location data we detected 6752 likely

420 fishing days displayed by 193 fishing vessels in the region of this particular large MPA

421 over the course of two years (Fig. 2). This level of fishing effort is quite remarkable given

422 the extreme remoteness of this region of the Pacific (McCauley et al., 2013). It is

423 important to recall that this represents a lower bound estimate of total fishing effort near

424 this large MPA since smaller vessels do not transmit AIS and some vessels do not

425 properly use this tracking system (McCauley et al., 2016).

426 We see in these outputs virtually no fishing pressure inside both the Palmyra Atoll

427 NWR and the U.S. EEZ, suggesting that large-scale spatial management can effectively

428 reduce fishing pressure on mobile species if enforcement is adequate. Fishing vessels

429 from Asia, Oceania, Europe, North America, Central America, and South America were

430 active in our study region, underscoring the globalized nature of addressing management

431 for mobile species, like grey reef sharks (Fig 3.). The majority of the detected vessels

432 were from East Asian nations, which could prove problematic for shark conservation

433 since the region is a major driver of the shark fin trade. These kinds of new observations

434 highlight the value of using emerging data sources on vessel activity to examine overlap

435 between the spatial ecology of marine apex predators and human predators - and the role

436 of MPAs in mediating these interactions. Future work that engages AIS data can be put to 
437 work for myriad allied applications, such as examining competition between fish and

438 fishermen for forage fish, examining the spatial dynamics of human-marine predator

439 interactions, and generating views of bycatch risk that are independent of fisheries

440 reporting data.

441 Our simple analysis of historical and potential MPA expansion scenarios suggest

442 that enlargement of this MPA has and would, respectively, decrease the amount of time

443 grey reef sharks spend outside protected areas. Every satellite-tagged shark left the

444 historical, 12 NM boundaries of Palmyra Atoll NWR, while only 2 sharks swam beyond

445 the maximum potential 200 NM limit (Table 1). Through the analysis of AIS detections,

446 we observe minimal differences in fishing effort within the MPA compared with EEZ

447 waters. The U.S. EEZ appears to be functioning as a de facto region of reduced fishing

448 effort, though smaller vessels that do not transmit AIS may be fishing in this region. In

449 this case, expanding large MPAs may prevent future spatial expansion of fishing, while

450 addressing additional stressors besides fishing. For instance, deep-ocean mining is

451 emerging as a major threat to slow-growing ecosystems across much of the planet

452 (Mengerink et al., 2014), and the recent expansion of PRINMN and the

453 Papahānaumokuākea Marine National Monument directly ensure that mining contracts

454 will not be granted throughout these immense protected regions.

455 In more heavily fished EEZs, expansions of large MPA boundaries - if properly

456 enforced - would decrease the amount of time grey reef sharks and other mobile

457 organisms spend exposed to elevated risk of fishing mortality. Future work should

458 explicitly explore what this added protection means to the population dynamics and

459 persistence of this and other at-risk species, but for shark species with low reproductive 
460 rates and high sensitivity to fishing pressure, increases in protection of this magnitude

461 may confer meaningful benefits. These results parallel observations in the central Pacific

462 that showed that seabirds, another ecologically important class of marine predator, travel

463 and forage beyond large MPA boundaries (e.g. red-footed boobies at Palmyra NWR

464 spent $33 \%$ of their time outside of the MPA boundaries; Young et al., 2015) and that sea

465 turtles populations maintain connectivity across protected and fished regions (Naro-

466 Maciel et al., 2014). While it is clear that large MPAs offer crucial protection for many

467 highly vagile and threatened species, these results also make it equally clear that it would

468 be prudent to develop diverse portfolios of conservation measures. Many large marine

469 vertebrates (mammal, reptile, and fish) are likely to be similar to grey reef sharks in that

470 some proportion of the their ecology will spill out beyond the boundaries of even the

471 largest politically tenable MPAs. Consequently, large MPAs will become much more

472 effective if they are matched with other non-place-based conservation strategies such as

473 gear restrictions, catch limits, and dynamic, temporal closures (Maxwell et al., 2015).

\section{$475 \quad 4.1$ Conclusions}

476 The establishment of very large MPAs in the last five years has far outpaced 477 research on the ecological effectiveness of these MPAs. Reviews and commentaries have 478 highlighted both the potential benefits of large MPAs (Koldewey et al., 2010; Lubchenco 479 and Grorud-Colvert, 2015) and skepticism of their utility (Dulvy et al., 2013; Hilborn et 480 al., 2015). Here we show how uniting the insight of new satellite tracking data for marine 481 species with emerging datasets on fishing effort can help resolve the value of large 482 MPAs. In the case of grey reef sharks, large MPAs unambiguously confer substantial 
protection to this at-risk species, though this protection is not complete for particularly

484 mobile individuals. Recent expansions of this MPA's boundaries have reduced the

485 potential for sharks to overlap with industrial fisheries, but some grey reef sharks transit

486 beyond the $200 \mathrm{NM}$ maximum potential limit of a MPA and in so doing interact with

487 small-scale and industrial fisheries. The process of drawing out these conclusions

488 provides a valuable model for strategically assessing the effectiveness of large MPAs for

489 other mobile species across the burgeoning number of marine regions where large MPAs

490 are being established.

\section{Acknowledgments}

493 We are grateful to the Fisheries Division of Kiribati and the communities of Kiritimati, 494 Tabuaeran, and Teraina for improving this work with logistical support and research 495 partnership. We also thank the staff and researchers of the Palmyra Atoll Research 496 Consortium (PARC) for facilitating research at Palmyra Atoll and Global Fishing Watch 497 for facilitating remote sensing of fishing effort. We thank three anonymous reviewers and 498 D. Friedman for providing helpful comments on this manuscript. This work was 499 supported by a grant from the Euro-Mediterranean Center on Climate Change and the 500 National Science Foundation's Graduate Research Fellowship Program.

\section{REFERENCES}

503 Bailey H, Shillinger G, Palacios D, Bograd S, Spotila J, Paladino F, Block B. 2008. Identifying 504 and comparing phases of movement by leatherback turtles using state-space models. $505 \quad$ Journal of Experimental Marine Biology and Ecology 356:128-135.

506 Barnett A, Abrantes KG, Seymour J, Fitzpatrick R. 2012. Residency and Spatial Use by Reef 507 Sharks of an Isolated Seamount and Its Implications for Conservation. PLoS ONE 508 (e36574) DOI: 10.1371/journal.pone.0036574 
Bez N, Walker E, Gaertner D, Rivoirard J, Gaspar P, Walters C. 2011. Fishing activity of tuna purse seiners estimated from vessel monitoring system (VMS) data. Canadian Journal of Fisheries and Aquatic Sciences 68:1998-2010.

512 Block BA, et al., 2011. Tracking apex marine predator movements in a dynamic ocean. Nature 475:86-90.

514 Bouchard SS, Bjorndal KA. 2000. Sea Turtles as Biological Transporters of Nutrients and Energy 515 from Marine to Terrestrial Ecosystems. Ecology 81:2305-2313.

516 Breed GA, Costa DP, Goebel ME, Robinson PW. 2011. Electronic tracking tag programming is 517 critical to data collection for behavioral time-series analysis. Ecosphere 2:1-12.

518 Cortés E. 2000. Life History Patterns and Correlations in Sharks. Reviews in Fisheries Science 8:299-344.

520 Compagno LJ. 2001. Sharks of the world: an annotated and illustrated catalogue of shark species

521 known to date. Food and Agriculture Organization of the United Nations, Rome, Italy.

522 Costa DP, et al., 2010. Accuracy of ARGOS Locations of Pinnipeds at-Sea Estimated Using

$523 \quad$ Fastloc GPS. PLoS ONE (e8677) DOI: 10.1371/journal.pone.0008677.

524 Davidson LNK. 2012. Shark Sanctuaries: Substance or Spin? Science 338:1538-1539.

525 De Santo EM. 2013. Missing marine protected area (MPA) targets: How the push for quantity 526 over quality undermines sustainability and social justice. Journal of Environmental $527 \quad$ Management 124:137-146.

528 Dueri S, Maury O. 2012. Modelling the effect of marine protected areas on the population of 529 skipjack tuna in the Indian Ocean. Aquatic Living Resources 26:171-178.

530 Dulvy NK. 2013. Super-sized MPAs and the marginalization of species conservation. Aquatic 531 Conservation: Marine and Freshwater Ecosystems 23:357-362.

532 Dulvy NK, et al., 2014. Extinction risk and conservation of the world's sharks and rays. eLife 533 (e00590) DOI: 10.7554/eLife.00590. 
534 Espinoza M, Heupel MR, Tobin AJ, Simpfendorfer, CA. 2015a. Residency patterns and

535 movements of grey reef sharks (Carcharhinus amblyrhynchos) in semi-isolated coral reef

536 habitats. Marine Biology 162:343-358.

537 Espinoza M, Lédée EJI, Simpfendorfer CA, Tobin AJ, Heupel MR. 2015b. Contrasting

538 movements and connectivity of reef-associated sharks using acoustic telemetry:

539 implications for management. Ecological Applications 25:2101-2118.

540 Estes JA, et al., 2011. Trophic Downgrading of Planet Earth. Science 333:301-306.

541 Ferretti F, Worm B, Britten GL, Heithaus MR, Lotze HK. 2010. Patterns and ecosystem

542 consequences of shark declines in the ocean. Ecology Letters 13:1055-1071.

543 Friedlander AM, Caselle JE, Ballesteros E, Brown EK, Turchik A, Sala E. 2014. The Real

544 Bounty: Marine Biodiversity in the Pitcairn Islands. PLoS ONE (e100142) DOI:

$545 \quad$ 10.1371/journal.pone.0100142.

546 Gaines SD, White C, Carr MH, Palumbi SR. 2010. Designing marine reserve networks for both

547 conservation and fisheries management. Proceedings of the National Academy of

$548 \quad$ Sciences 107:18286-18293.

549 Game ET, Grantham HS, Hobday AJ, Pressey RL, Lombard AT, Beckley LE, Gjerde K,

550 Bustamante R, Possingham HP, Richardson AJ. 2009. Pelagic protected areas: the

551 missing dimension in ocean conservation. Trends in Ecology \& Evolution 24:360-369.

552 Graham NAJ, Spalding MD, Sheppard CRC. 2010. Reef shark declines in remote atolls highlight

553 the need for multi-faceted conservation action. Aquatic Conservation: Marine and

$554 \quad$ Freshwater Ecosystems 20:543-548.

555 Graham RT, Witt MJ, Castellanos DW, Remolina F, Maxwell S, Godley BJ, Hawkes LA. 2012.

556 Satellite Tracking of Manta Rays Highlights Challenges to Their Conservation. PLoS

557 ONE (e36834) DOI: 10.1371/journal.pone.0036834.

558 Halpern BS, Lester SE, Kellner JB. 2009. Spillover from marine reserves and the replenishment

$559 \quad$ of fished stocks. Environmental Conservation 36:268-276. 
560 Heupel MR, Simpfendorfer CA, Fitzpatrick R. 2010. Large-Scale Movement and Reef Fidelity of 561 Grey Reef Sharks. PLoS ONE (e9650) DOI: 10.1371/journal.pone.0009650.

562 IUCN (International Uniov for Conservation of Nature). 2015. The IUCN Red List of Threatened 563 Species. Version 2015.4. IUCN, Gland, Switzerland. Available from

564 http://www.iucnredlist.org/ (accessed May 2016).

565 Jonsen ID, Flemming JM, Myers RA. 2005. Robust State-Space Modeling of Animal Movement 566 Data. Ecology 86:2874-2880.

567 Koldewey HJ, Curnick D, Harding S, Harrison LR, Gollock M. 2010. Potential benefits to

568 fisheries and biodiversity of the Chagos Archipelago/British Indian Ocean Territory as a 569 no-take marine reserve. Marine Pollution Bulletin 60:1906-1915.

570 Lubchenco J, Grorud-Colvert K. 2015. Making waves: The science and politics of ocean $571 \quad$ protection. Science 350:382-383.

572 Lubchenco J, Palumbi SR, Gaines SD, Andelman S. 2003. Plugging A Hole In The Ocean: The 573 Emerging Science Of Marine Reserves. Ecological Applications 13:3-7.

574 Maxwell SM, et al., 2015. Dynamic ocean management: Defining and conceptualizing real-time 575 management of the ocean. Marine Policy 58:42-50.

576 McCauley DJ, Young HS, Dunbar RB, Estes JA, Semmens BX, Micheli F. 2012. Assessing the 577 effects of large mobile predators on ecosystem connectivity. Ecological Applications $578 \quad 22: 1711-1717$.

579 McCauley DJ, Power EA, Bird DW, Mcinturff A, Dunbar RB, Durham WH, Micheli F, Young 580 HS. 2013. Conservation at the edges of the world. Biological Conservation 165:139-145.

581 McCauley DJ. 2014. Mega-parks need greater oversight. Nature 515:29.

582 McCauley DJ, Pinsky ML, Palumbi SR, Estes JA, Joyce FH, Warner RR. 2015. Marine

583 defaunation: Animal loss in the global ocean. Science 347:1255641-1255641.

584 McCauley DJ, Woods P, Sullivan B, Bergman B, Jablonicky C, Roan A, Hirshfield M, Boerder

585 K, Worm B. 2016. Ending hide and seek at sea. Science 351:1148-1150. 
McKibben JN, Nelson DR. 1986. Patterns of movement and grouping of gray reef sharks, Carcharhinus amblyrhynchos, at Enewetak, Marshall Islands. Bulletin of Marine Science 38:89-110.

Mengerink KJ, et al. 2014. A Call for Deep-Ocean Stewardship. Science 344:696-698.

590 Moffitt EA, Botsford LW, Kaplan DM, O'Farrell MR. 2009. Marine reserve networks for species that move within a home range. Ecological Applications 19:1835-1847.

Naro-Maciel E, Gaughran SJ, Putman NF, Amato G, Arengo F, Dutton PH, McFadden KW, Vintinner EC, Sterling EJ. 2014. Predicting connectivity of green turtles at Palmyra Atoll, central Pacific: a focus on mtDNA and dispersal modelling. Journal of The Royal Society Interface 11:20130888.

Pala C. 2013. Giant Marine Reserves Pose Vast Challenges. Science 339:640-641.

Queiroz N, Humphries NE, Mucientes G, Hammerschlag N, Lima FP, Scales KL, Miller PI, Sousa LL, Seabra R, Sims DW. 2016. Ocean-wide tracking of pelagic sharks reveals extent of overlap with longline fishing hotspots. Proceedings of the National Academy of Sciences 113:1582-1587.

604 Randall JE. 2007. Reef and Shore Fishes of the Hawaiian Islands. University of Hawaii Press, 605 Honolulu, Hawaii.

606 Robbins WD, Hisano M, Connolly SR, Choat JH. 2006. Ongoing Collapse of Coral-Reef Shark 607 Populations. Current Biology 16:2314-2319.

608 Roberts CM, Bohnsack JA, Gell F, Hawkins JP, Goodridge R. 2001. Effects of Marine Reserves 609 on Adjacent Fisheries. Science 294:1920-1923. 
610 Rosenbaum HC, Maxwell SM, Kershaw F, Mate B. 2014. Long-Range Movement of Humpback

611 Whales and Their Overlap with Anthropogenic Activity in the South Atlantic Ocean.

$612 \quad$ Conservation Biology 28:604-615.

613 Sandin SA, et al. 2008. Baselines and Degradation of Coral Reefs in the Northern Line Islands.

$614 \quad$ PLoS ONE (e1548) DOI: 10.1371/journal.pone.0001548.

615 Sibert J, Senina I, Lehodey P, Hampton J. 2012. Shifting from marine reserves to maritime

616 zoning for conservation of Pacific bigeye tuna (Thunnus obesus). Proceedings of the

$617 \quad$ National Academy of Sciences 109:18221-18225.

618 Stevenson C, Katz LS, Micheli F, Block B, Heiman KW, Perle C, Weng K, Dunbar R, Witting J.

619 2006. High apex predator biomass on remote Pacific islands. Coral Reefs 26:47-51.

620 Tekaieti, A. 2012. Report on the Kiribati 2010 census of population and housing. Kiribati

$621 \quad$ National Statistics Office, Tarawa, Kiribati.

622 White ER, Myers MC, Flemming JM, Baum JK. 2015. Shifting elasmobranch community

623 assemblage at Cocos Island — an isolated marine protected area. Conservation Biology

$624 \quad 29: 1186-1197$.

625 Winship AJ, Jorgensen SJ, Shaffer SA, Jonsen ID, Robinson PW, Costa DP, Block BA. 2012.

626 State-space framework for estimating measurement error from double-tagging telemetry

627 experiments. Methods in Ecology and Evolution 3:291-302.

628 Young HS, Maxwell SM, Conners MG, Shaffer SA. 2015. Pelagic marine protected areas protect

629 foraging habitat for multiple breeding seabirds in the central Pacific. Biological

$630 \quad$ Conservation 181:226-235. 
633 Table 1. The percentage of state-space modeled daily location estimates and maximum distance beyond the previous (12 nautical mile,

634 NM), current (50 NM), and maximum potential (200 NM) boundaries for Palmyra Atoll National Wildlife Refuge.

\begin{tabular}{|c|c|c|c|c|c|c|c|c|c|c|c|c|}
\hline \multirow[b]{2}{*}{ Tag ID } & \multirow[b]{2}{*}{ Sex } & \multirow[b]{2}{*}{$\begin{array}{l}\text { Total } \\
\text { length } \\
(\mathrm{cm})\end{array}$} & \multirow[b]{2}{*}{$\begin{array}{c}\text { Days } \\
\text { at } \\
\text { liberty }\end{array}$} & \multirow[b]{2}{*}{$\begin{array}{c}\text { Detections } \\
\text { (n) }\end{array}$} & \multirow[b]{2}{*}{$\begin{array}{c}\text { Detections } \\
\text { in pelagic } \\
\text { waters } \\
(\%)\end{array}$} & \multicolumn{3}{|c|}{ Positions beyond MPA boundary (\%) } & \multicolumn{4}{|c|}{ Maximum distance beyond boundary $(\mathrm{km})$} \\
\hline & & & & & & $12 \mathrm{NM}$ & $50 \mathrm{NM}$ & $200 \mathrm{NM}$ & $\begin{array}{c}\text { Palmyra } \\
\text { Atoll } \\
500 \mathrm{~m} \\
\text { isobath }\end{array}$ & $12 \mathrm{NM}$ & $50 \mathrm{NM}$ & $200 \mathrm{NM}$ \\
\hline 129825 & $M$ & 148 & 40 & 51 & 24 & 4.8 & 0.0 & 0.0 & 40.4 & 22.1 & - & - \\
\hline 129874 & M & 143 & 204 & 32 & 44 & 18.8 & 9.4 & 3.1 & 182.1 & 166.0 & 88.1 & 19.1 \\
\hline 129875 & M & 156 & 390 & 179 & 13 & 4.6 & 0.0 & 0.0 & 88.6 & 72.0 & - & - \\
\hline 129876 & M & 143 & 466 & 154 & 6 & 0.8 & 0.0 & 0.0 & 18.7 & 6.3 & - & - \\
\hline 131941 & M & 150 & 139 & 89 & 31 & 4.3 & 0.0 & 0.0 & 43.8 & 22.0 & - & - \\
\hline 131942 & $\mathrm{M}$ & 151 & 237 & 375 & 97 & 63.8 & 57.0 & 46.3 & 926.3 & 907.7 & 809.7 & 617.6 \\
\hline Median & - & 149.0 & 220.5 & 121.5 & 27.5 & 4.7 & 0.0 & 0.0 & 66.2 & - & - & - \\
\hline
\end{tabular}


635 Table 2. Coastal fishermen operating beyond the Palmyra Atoll National Wildlife

636 Refuge's boundaries captured 5 of 262 grey reef sharks that were initially tagged within

637 the MPA, indicating shark movements of up to $366 \mathrm{~km}$.

\begin{tabular}{ccccc}
\hline Days at liberty & Sex & Total length $(\mathrm{cm})$ & $\begin{array}{c}\text { Recapture } \\
\text { location }\end{array}$ & $\begin{array}{c}\text { Distance shark } \\
\text { travelled }(\mathrm{km})\end{array}$ \\
\hline 68 & $\mathrm{~F}$ & 130 & Teraina & 223 \\
152 & $\mathrm{~F}$ & 154 & Tabuaeran & 366 \\
461 & $\mathrm{~F}$ & 155 & Tabuaeran & 366 \\
834 & $\mathrm{~F}$ & 133 & Tabuaeran & 366 \\
1420 & $\mathrm{~F}$ & 144 & Teraina & 223 \\
\hline
\end{tabular}

638

639

640

641

642 Table 3. Core areas (50\% Kernel Utilization Distribution, or KUD) and activity space

643 (95\% KUD) of six grey reef sharks that were satellite tagged at Palmyra Atoll.

\begin{tabular}{ccccc}
\hline \multirow{2}{*}{ Tag ID } & Sex & Total length $(\mathrm{cm})$ & 50 \% KUD $\left(\mathrm{km}^{2}\right)$ & 95 \% KUD $\left(\mathrm{km}^{2}\right)$ \\
\hline 129825 & M & 148 & 192 & 950 \\
129874 & M & 143 & 757 & 5,442 \\
129875 & M & 156 & 116 & 915 \\
129876 & M & 143 & 24 & 217 \\
131941 & M & 150 & 104 & 857 \\
131942 & M & 151 & 106,049 & 412,189 \\
Median & - & 149 & 154 & 933 \\
\hline
\end{tabular}

644

645

646 

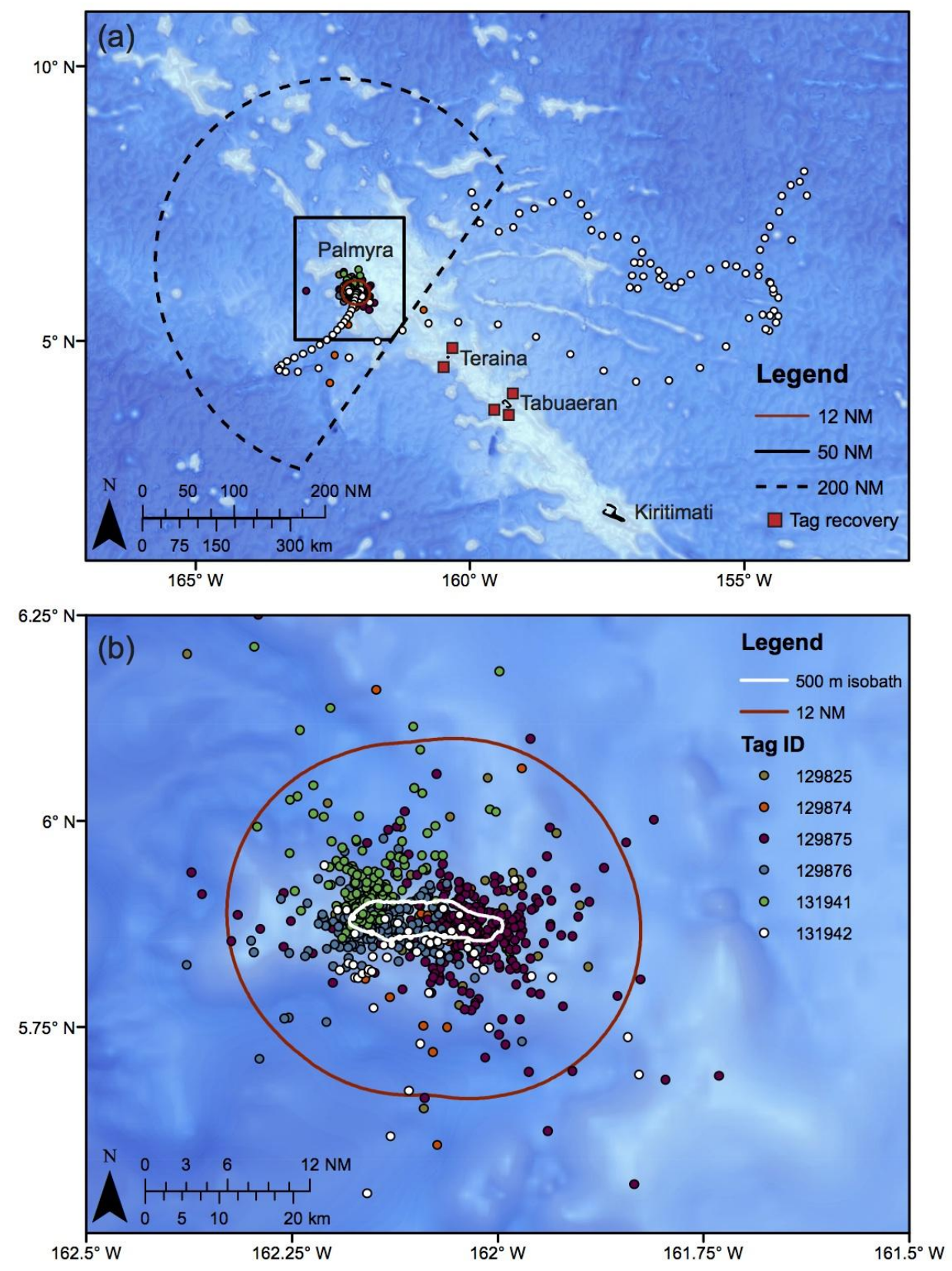

667 Figure 1. (a) The state-space modeled daily position estimates for 6 sharks fitted with

668 satellite tags at Palmyra Atoll and (b) the subset of those positions surrounding

669 Palmyra Atoll. 


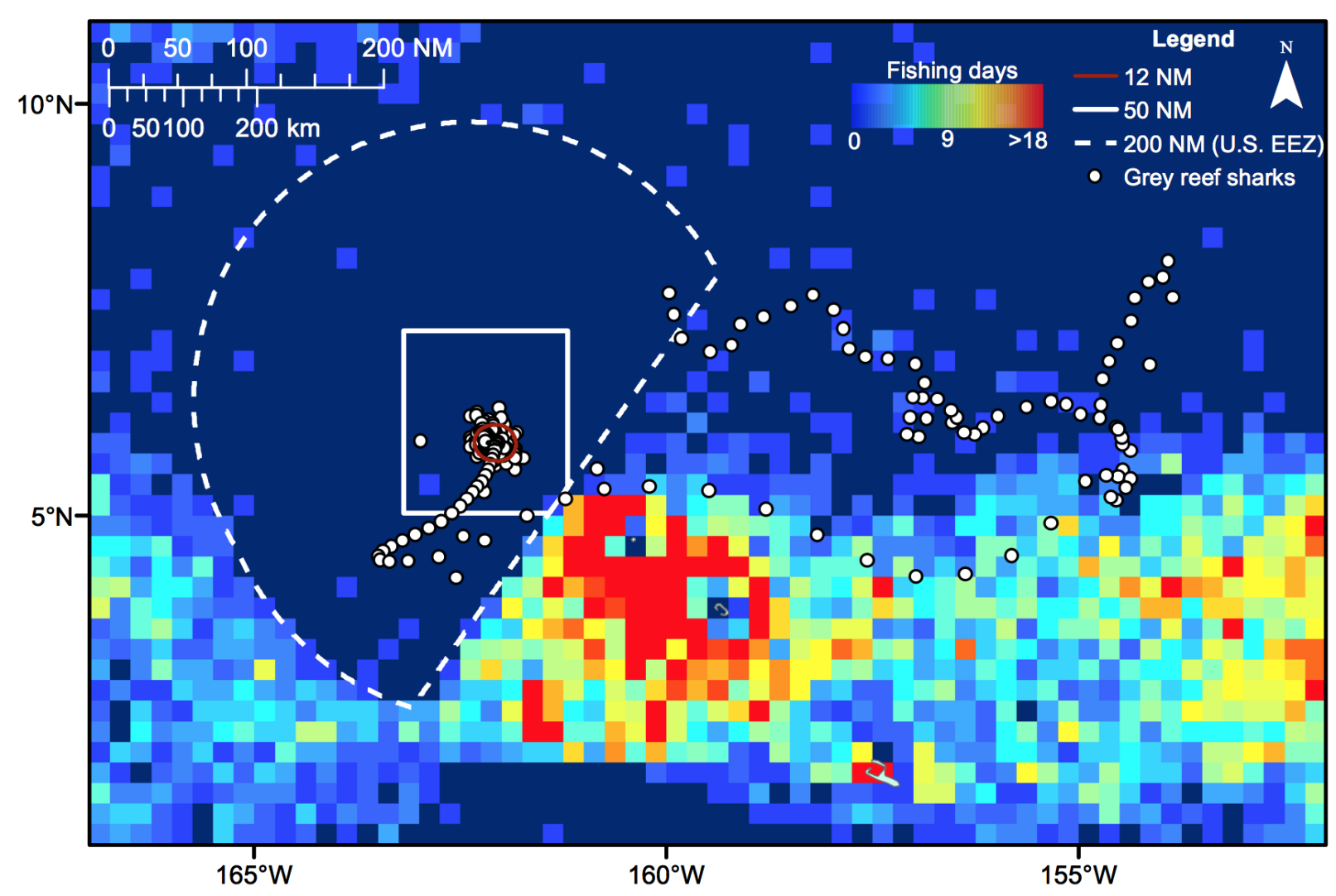

670

671 Figure 2. A fishing effort density map for 193 commercial fishing vessels as determined

672 through remote sensing of vessel Automatic Identification System (AIS) transmissions.

673 Grid size is $0.25^{\circ}$.

674

675

676

677

678

679 


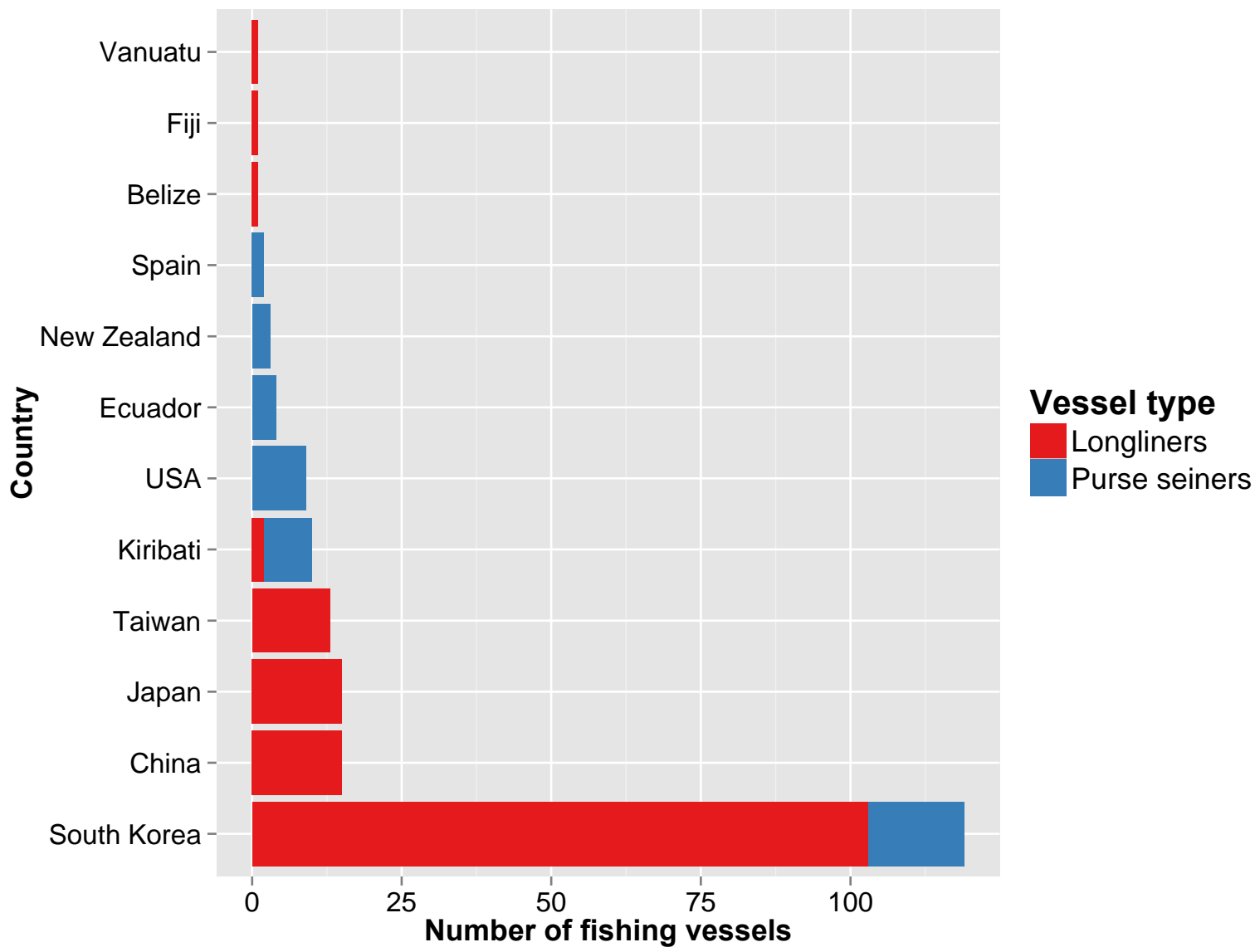

683 Figure 3. The nationality and fishing method used by the 193 fishing vessels that we 684 observed in our study region. 